\title{
Artificial Intelligence and Business Leadership Development: Applications and Solutions
}

\author{
Enoch O. Antwi. EdD. \\ Assistant Professor \\ Dahl School of Business \\ Viterbo University \\ La Crosse, WI, 54602, USA \\ E-mail: eantwi@viterbo.edu \\ Phone: 6087963377 \\ USA
}

\section{ABSTRACT}

Artificial intelligence (AI) is the promise of today and future businesses. Any leadership development model that ignores AI could miss out on modern business tools, technology, and resources. Though evaluations in developing business leaders present a positive relationship between AI and leadership development (Husain, 2017; Reese, 2018; Hosanagar, 2019), not many studies have been conducted in these areas. With Roomba Robots listening to social media and iRobot's identifying customers and reaching out to them through private channels (Carr, 2011), a question arises: will AI be required to use business leadership practices in solving applicable challenges, or it will just be a marketing tool? Leadem (2017) quoted Colin Angle, iRobot's founder, and CEO in an Entrepreneur Magazine, "I have been able to remain CEO, not because of the fact I was CEO yesterday, but because I've worked very hard to listen, learn and evolve in the seat." Developing business leaders could be rooted in AI knowledge, applicability, challenges, and solutions while paying attention to the three keywords of listening, learning, and evolving in leadership.

\section{Keywords: Business, Leadership development, Artificial Intelligence, Solutions, Applications.}

I. The Flux and AI Infiltrating More of the Operational Functions.

The shortfalls in developing business leaders appear to hinge on a lack of business application and solution tools as well as effective leadership models. This review provides a snapshot of the current state of business leadership in decisionmaking, where AI is being deployed, and possible routes to improve solutions for business leaders. Tegmark (2017) argued that intelligence is the ability to accomplish complex goals. As the world becomes more complex, diverse, and ambiguous (Bird \& Osland, 2004), interdependence is imminent. Artificial Intelligence appears to infiltrate more of the operational functions of the business as numerous stories unfold of developments, fears, and opportunities for the future.

Some businesses have gained from AI while others have lost. Davies \& Ruche (2019) found Facebook's massive data collection and sale to Cambridge Analytica for targeted algorithmic use during the 2016 United States elections, which resulted in a \$US5billion fine. In another study, German (2019) found a moral gap in the grounding of the Boeing 737 Max 8 due to a glitch in its autopilot system that caused two planes to crash, killing hundreds of passengers.

The question is, are those in business leadership positions prepared adequately and developed appropriately for this AI-driven business and societal challenges? Can the quest of developing business leadership be a guiding force in the creation of a framework of AI ethics to guide AI development for a better tomorrow? Kyte (2016) argued for a solid moral foundation, citing underappreciated traits in ethical decisions as moral imagination, and calling for a look at situations critically and creatively in redressing the wrongs, avoiding harm and enhancing common good in creating the right foundation to build future ethical conduct on.

Technology is our roommate now. Most people work from home. Most instructional materials are delivered online. Zoom is becoming a verb just like Google. Listening, learning, and evolving needs technology now more than ever. However, the use of various technologies, including AI presents algorithm architects and possible existential threats. Ethical solutions and applications appear minimal. Intertwining the core values of business leadership into a world that changes rapidly through technological advances amid the flux seems daunting.

\section{The Test: AI and Business Leadership Correlation.}

Business leaders need a litmus test to speed up the chemical reaction of applications, solutions, and decisions. The gap in understanding modern business leadership and AI correlations and relations keeps widening. Worse still, there are few national and global AI oversight boards, which leaves control mechanisms to corporations themselves (Hosanagar, 2019). This is a grey area if we are developing business leaders for the future. Other grey area is closing the business leadership and AI gap. Yet, there is another. Data on AI about business leadership is scanty, secretive, and non-existent in 


\title{
International Journal of Business and Applied Social Science (IJBASS)
}

\author{
E-ISSN: 2469-6501 \\ VOL: 7, ISSUE: 11 \\ November/2021 \\ DOI: http://dx.doi.org/10.33642/ijbass.v7n11p2 \\ (c) (i) \\ https://creativecommons.org/licenses/by/4.0/
}

most cases, especially, on algorithmic development. The least said about other countries where governments intervene in business practices, the better. Artificial Intelligence is the future of business. Yet, the future is unknown. And, what leaders don't know could also be intimidating. This review initiates a talk of the unknown future and points out the challenges and opportunities for development purposes. Russia President, Vladimir Putin said something to Russian Children on Knowledge Day (1 September 2017). It is worth quoting in extenso:

Artificial intelligence is the future, not only for Russia but for all humankind. It comes with colossal opportunities, but also threats that are difficult to predict. Whoever becomes the leader in this sphere will become the ruler of the world.

Though a political talk, check recent hacks, virus threats, phishing, and general privacy and security challenges, including social media, using targeted algorithms, and other cyber warfare that affects businesses. A business leader ignores those threats at his or her own risk.

\section{Significance of This Review}

Artificial General Intelligence (AGI) could be $P$ unleashed onto the internet by even a teenager and executed on a keyboard. Simple sloppy programming combined with giving an AGI great cognitive power could yield disaster for many businesses. Reese (2018) posited that an AGI tasked with cleaning up the environment could erroneously conclude that the best strategy is to get rid of all the people" (Reese, 2018 , p. 184). If this is not serious for business leaders to pay attention to, then I don't know what is. In a related study, Harari (2018) asked, "What's enabling humans in achieving the creation of an intelligent, possibly someday sentient, nonorganic "being" is the rise of Big Data, neural nets, recursive and adversarial machine learning, and genetic algorithms, all combined with blazingly fast computing power? (p. 31). He further queried,

"Can you guess how long it took AlphaZero to learn chess from scratch, prepare for the match against Stockfish [the world's computer chess champion for 2016], and develop its genius instinct? Four hours! Yes, only four hours. For centuries, chess was considered one of the crowning glories of human intelligence. AlphaZero went from utter ignorance to creative mastery in four hours, without the help of any human guide" (Harari, 2018, p. 31-32).

You should be scratching your head, thinking the quote above is an opportunity or a threat to business. Can we poke the answer in the middle of the flux? Multiple institutional systems such as the electrical grid, financial markets, and healthcare are now networked with information and operational systems, which are dependent on connectivity to the point any small deviation, glitch or hack can crash its infrastructure. Even though the intra and inter-connectivity are valuable for the functioning of the system, it raises the risk of cascading failures, such as a small substation being hacked and failing, which in turn causes others to fail, and finally taking out the power grid for millions of people in multiple states or countries.

\section{Current Regulations.}

There is very little enforceable regulation or oversight of AI applications. Few institutions such as the Institute for Ethics and Emerging Technologies, The Future of Life Institute, and Open Roboethics Initiative are creating awareness of vital needs for an ethical framework to keep humans and AI. Husain (2017) argued "I want my generation to be prepared, and preparation means developing technology to manage these viable threats. We can't depend on more unenforceable bans and treaties. We need next-generation AIbased technology. And we need to foment societal discourse that leads to a balanced view of artificial intelligence" (Husain, 2017 , p. 171). Few academic conferences also seek to wage into the AI-business leadership argument. In January 2017, at a conference titled Beneficial AI in Asilomar, California, organized by the Future of Life Institute, scientists, researchers, government representatives, and ethicists discussed issues about AI and came out with what they called the AI Asilomar Principles, a list of 23 principles and guidelines organized into three sections: Research related Ethics and Values, and Futuristic/Long-term issues.

\section{The AI Challenge-The Bad}

Artificial Intelligence (AI) can go bad. Transparency is sketchy. Think about how AI gets to its decisions. Often called the "black box" problem. In this process, data is fed into the algorithm, an answer is reached, and we have no idea how it reached that answer. It's also referred to as "Alien Intelligence." Algorithms are often the "secret sauce" of an AI's functioning and are kept very private or proprietary. Business leadership development for a better tomorrow must seek more transparency in how these algorithms work, as decisions that affect people's lives are being based on how those algorithms to process information, often without any recourse (Hosanagar, 2019).

The business community calls for oversight of data; how data is collected, "cleaned up" (which can also introduce biases), and who is ultimately responsible for its execution, in not out of order. Just as biases in research are a serious ethical breach, biases in algorithmic development need to be addressed, in that both data and "black box" algorithms are the mechanisms that produce the answers, and these answers can be skewed due to corrupt data or a poorly written algorithm. Bostrum (2014) found that most AI-related professionals are male and either white or Asian. For AI to truly progress, it needs a full representation of humanity to more accurately reflect fairly on the world around us. These biases affect many different areas where they're being used: policing, college admissions, credit rating, insurance rates, and other businessrelated and leadership development areas.

Hosanagar (2019), proposed an "Algorithmic Bill of Rights" which covers four different areas of algorithmic applications and addresses issues of the potential impacts of 


\title{
International Journal of Business and Applied Social Science (IJBASS)
}

\author{
E-ISSN: 2469-6501 \\ VOL: 7, ISSUE: 11 \\ November/2021 \\ DOI: http://dx.doi.org/10.33642/ijbass.v7n11p2 \\ https://creativecommons.org/licenses/by/4.0/
}

how algorithms are used; data collected, and responsibility for the results. He sought transparency in the design, deployment, and implementation of algorithmic transactions, and proposed an Algorithmic Right, which includes: (a) A description of the data used to train an algorithm, (b) Easily explainable procedures used by the algorithm that anyone could understand, (c) Some level of control in how the algorithms work, including a feedback loop, and (d) Responsibility for unintended consequences when using programmed decisionmaking. These experts' proposals seem to communicate a looming danger that academia and business leaders cannot ignore.

\section{The Good}

Artificial Intelligence is a huge economic, revenuegenerating machine. World economies generate millions of revenues from AI. Bughin (2018) posited that AI has the potential to deliver additional global economic activity of around $\$ 13$ trillion by 2030 , or about 16 percent higher cumulative GDP compared with today. This amounts to 1.2 percent additional GDP growth per year in world economies. Havens (2016) had a great submission:

"This is where I think AI and emerging tech will be most beneficial where we can know how we're projecting our identity to the world so we can give and get all we need to increase well-being without money. It may sound complicated, but so is replicating the human mind and imbuing machines with consciousness" (Havens, 2016, p. 199).

\section{Biggest Concern-Loss of Jobs.}

Artificial Intelligence raises a huge concern for labor and the world of work. In August 2020, iRobot launched a new software platform aimed at making its robots even smarter (Chesto, 2020). How are business leaders being trained to become smarter? Note that academia is the supply side of employment. The demand side is industry and corporate of potential employers. Academia trains individuals for the world of work. With the spread of AI into the workplace and a costeffective potential to replace millions of people, job losses are imminent. Estimates range from $10-50 \%$ of all jobs being replaced by AI agents by 2050 (Jasanoff, 2016; Reese, 2018; Seldon and Abidoye, 2018; Walsh 2019). Job losses due to automation and AI-enhanced agents replacing humans presents three scenarios according to Reese (2018): Scenario One robots and AI will take all of the jobs; Scenario Two- robots and AI will take some of the jobs, and Scenario-Three- robots and AI will take none of the jobs. Reese (2018) logically pieces together and construes each scenario, setting the stage for this new working world order. It's a practical thought exercise, one that many people (especially for those with jobs that are easily automated) should think through now, as they are most vulnerable to having their jobs replaced. The amount of business leadership reeducation, retraining, and reskilling required could be large in scale and scope. This seems to be an area where leadership is lacking. Interfaces as control mechanisms present privacy challenges and intelligence could replace humans. Rushkoff (2019) rung the alarm bell that they are deployed in concert with the demands of the marketplace, political sphere, and power structure that depend on human isolation and predictability to operate (p. 5).

Proactiveness is key. Once the waves of massive layoffs begin, it'll be too late for many families and economies.

Being proactive also means reviewing educational curriculum and course designs to meet the competencies of future business needs. Sarangi \& Sharma (2019) argued that without such reviews, the importance of obtaining a higher education could become irrelevant in the future. They believed that if a college degree was the path to better employment, and then that job is eliminated or taken by an AI agent, what's the necessity in obtaining that degree? That raises the question of possible portions of higher education becoming extraneous if not reviewed and modified. Seldon and Abidoye (2018) posited that the educational system needs complete revamping to tackle the challenges of an AI-enhanced world to prepare students for a wildly different workplace landscape of employment challenges. Business leadership development in this direction could lead stakeholders' homes.

Harari (2018) pointed out what should be taught now in 'developing' instead of the current menu of fixed skills to prepare individuals for the looming, radical change: The four Cs'-Critical thinking, Communication, Collaboration, and Creativity. More importantly, Sarangi \& Sharma (2019), Seldon and Abidoye (2018), and Harari (2018) believe training should emphasize general-purpose life skills, which machines cannot replicate. They should be taught how to ask questions, not how to answer questions. Most important of all will be the ability to deal with change, learn new things, and preserve mental balance in unfamiliar situations" (Harari, 2018, p. 266).

Harari (2018) creates the urgency for business leadership: "We cannot wait for the crisis to erupt in full force before we start looking for answers. By then it will be too late. To cope with the unprecedented technological and economic disruptions of the twenty-first century, we need to develop new social and economic models as soon as possible. These models should be guided by the principle of protecting humans rather than jobs. ...We should focus instead on providing for people's basic needs and protecting their social status and self-worth" (Harari, 2018, p. 37). The leadership constructs of foresight and vision come in handy.

\section{Cultural Impacts}

The cultural piece of AI entails dangers, paths, and strategies (Bostron,2014). However, Peter Drucker argued that culture eats strategy for breakfast (Johnson, Whittington, and Scholes, 2012). Sarangi and Sharma (2019) theorized that AI could pose future evolution, ethics, and public policy challenges. Could AI potentially destabilize the social norms, traditions, and institutions with new Dos and Don'ts? In October 2017, Saudi Arabia granted the robot "Sophia" citizenship to their country. What are the ethical implications 


\author{
E-ISSN: 2469-6501 \\ VOL: 7, ISSUE: 11 \\ November/2021 \\ DOI: http://dx.doi.org/10.33642/ijbass.v7n11p2

for granting robot citizenship? Many have criticized this move by Saudi Arabia as "dehumanizing" or "devaluing" humans by equating a machine to a person. Which brings up the question of what does it mean to be human? What are humans for, and what is our purpose? Is the definition of human strictly about our biology? Intellect? Emotions? Consciousness? Sentience? Qualia?

"The robot, Sophia, has declared that she wants to use her unique position to fight for women's rights in the Gulf nation where laws allowing women to drive were only passed in 2016 and where a multitude of oppressive rules are still actively enforced (such as women still requiring a male guardian to make financial and legal decisions). Sophia seems to have more rights than women living in Saudi Arabia" (Sarangi \& Sharma, 2019, p.83).

\section{Conclusion}

Present business needs, trends, and projections in predicting the future of developing businesses leadership with substantial accuracy hinges on applications and solutions of AI. Business leaders need to be informed of these applications and solutions to develop effective mediation methodologies. Failure to do so could cause disaster in the future of business and an indictment on leadership. Artificial Intelligence has permeated each fiber of business and should be part and parcel of each leadership development discussion. The clever thing to do is to theorize ways of maintaining and controlling AI, and then it becomes ours to create an ideal business society. The challenge is, the "we" is a small group of elites (scientists, politicians, academia, and wealthy) trying to understand this phenomenon and interpret it in the context of business, leadership, and development. Artificial Intelligence agents are not perfect, just as business leaders are not perfect. We cannot over-rely or over-trust AI (Hosanagar, 2019). We are at the right place in developing business leaders with the right skills, attitudes, and abilities to listen, learn and evolve to create a better tomorrow. Education has always been part of every solution.

\title{
REFERENCES
}

Bird, A., \& Osland, J. S. (2004). Global Competencies: An Introduction. In H.W. Lane, M.L. Maznevski, M.E. Menddenhall, \& J. McNett (eds.). The Blackwell Handbook of Global Management: A Guide to Managing Complexity: Blackwell: 5780.

Bostrom, N. (2014). Superintelligence - Paths, Dangers, Strategies: Oxford University Press.

Bughin, J. (2018). Notes from the AI frontier: Modeling the impact of AI on the world economy. Retrieved from https://www.mckinsey.com/featured-insights/artificial-intelligence/notes-from-the-ai-frontier-modeling-the-impact-ofai-on-the-world-economy

Carr, D. (2011, September 28). Roomba Robots Listen to Social Media. Retrieved from https://www.informationweek.com/software/social/roomba-robots-listen-to-social-media/d/d-id/1100404

Chesto, J. (2020, August 25). iRobot launches new software platform aimed at making its robots smarter - The Boston Globe. Retrieved from https://www.bostonglobe.com/2020/08/25/business/irobot-launches-new-software-platform-aimedmaking-its-robots-smarter/

Davies, R., \& Rushe, D. (2019, July 24). Facebook to pay \$5bn fine as regulator settles Cambridge Analytica complaint. Retrieved from https://www.theguardian.com/technology/2019/jul/24/facebook-to-pay-5bn-fine-as-regulator-filescambridge-analytica-complaint.

German, K. (2019) “A Year after the First 737 Max Crash, It's Unclear When the Plane Will Fly Again.” CNET, www.cnet.com/news/boeings-737-max-8-all-about-the-aircraft-flight-ban-and-investigations/.

Harari, Y. (2018). 21 Lessons for the 21st Century: Spiegel \& Grau.

Havens, J. (2016). Heartificial Intelligence - Embracing Our Humanity to Maximize Machines: Jeremy P. Tarcher / Penguin.

Hosanagar, K. (2019). A Human's Guide to Machine Intelligence - How Algorithms Are Shaping Our Lives and How We Can Stay in Control. Viking / Penguin Random House.

Husain, A. (2017). The Sentient Machine - The Coming Age of AI. Scribner.

iRobot. (2020). History. Retrieved November 29, 2020, from https://www.irobot.com/about-irobot/company-information/history

iRobot. (2020). iRobot Unveils Personalized Cleaning Experiences Powered by iRobot Genius ${ }^{\mathrm{TM}}$ Home Intelligence. Retrieved from https://media.irobot.com/2020-08-25-iRobot-Unveils-Personalized-Cleaning-Experiences-Powered-by-iRobot-

Genius-TM-Home-Intelligence

Jasanoff, S. (2016) The Ethics of Invention - Technology and the Human Future: W. W. Norton \& Co. 
Johnson, G., Whittington, R., and Scholes, K. (2012). Fundamentals of Strategy. Pearson.

Kyte, R. (2016). Ethical Business: Cultivating the Good in Organizational Culture. Christian Brothers Publications.

Leadem, R. (2017, September 19). Why the Entrepreneur Behind iRobot, Which Has Sold More Than 20 Million Robots, Burns Frustrating Documents at the End of Every Year. Retrieved from https://www.entrepreneur.com/article/300547

Reese, B. (2018). The Fourth Age - Smart Robots, Conscious Computers and the Future of Humanity: Atria Books / Simon \& Schuster.

Reese, B. (2018). The Fourth Age - Smart Robots, Conscious Computers and the Future of Humanity: Atria Books / Simon \& Schuster.

Rushkoff, D. (2019). Team Human. W. W. Norton \& Company.

Santens, S. (2017). Artificial Intelligence and the Technological Singularity - Opposing Viewpoints Series, Various Authors: Greenhaven Publishing.

Sarangi S. \& Sharma, P. (2019). Artificial Intelligence - Evolution, Ethics and Public Policy. New: Routledge / Taylor \& Francis Group.

Saudi Arabia grants citizenship to robot Sophia. Retrieved from https://www.dw.com/en/saudi-arabia-grants-citizenship-to-robot-sophia/a-

41150856\#: :text=Saudi\%20Arabia\%20granted\%20citizenship\%20to,company\%20Hanson\%20Robotics\%20in\%2020 15.

Seldon, A. \& Abidoye, O. (2018). The Fourth Education Revolution - Will Artificial Intelligence Liberate or Infantilise Humanity? The University of Buckingham Press, Ltd.

Tegmark, M. (2017). LIFE 3.0 - Being Human in the Age of Artificial Intelligence: Vintage.

Walsh, B. (2019). End Times - A Brief Guide to the End of the World: Asteroids, Supervolcanoes, Rogue Robots, and More: Hachette Book Group.

'Whoever leads in AI will rule the world': Putin to Russian children on Knowledge Day. (n.d.). Retrieved from https://www.rt.com/news/401731-ai-rule-world-putin/. 